Mr Aleksandar Bukvić, potpukovnik, dipl. inž.

Vojnoizdavački zavod Beograd

\section{INDIKATORSKI POKAZATELJI RADA DIZEL MOTORA SA DIZEL GORIVOM D-2. BIODIZELOM RME I NJIHOVIM MESAVINAMA}

UDC: $621.436: 665.75$

Rezime:

S obzirom na to da su rezerve nafte, odnosno goriva mineralnog porekla ograničene, sve je aktuelniji trend istraživanja obnovljivih izvora goriva radi supstitucije konvencionalnih goriva. U poslednje vreme u svetu je aktuelna tendencija supstitucije mineralnih goriva za dizel motore gorivima na bazi biljnih kultura. Direktiva Evropske unije ukazuje na neophodnost supstitucije fosilnog dizel goriva sa 0,75\% biogoriva godišnje. U ukupnoj potrošnji biogorivo treba da učestvuje sa 5,75\% do 2010. godine, a do 2020. godine sa $20 \%$. U radu su prikazane tehnologije dobijanja biodizela i rezultati ispitivanja dizel motora $S$-44 sa primenom dizel goriva D-2, biodizela RME i njihovih mešavina. Rezultati navode na konstataciju da je potrebno dalje poboljšavati kvalitet takvih goriva, a naročito njihovih fizičko-hemijskih karakteristika, u skladu sa predloženim standardom za biodizel.

Ključne reči: dizel motor, dizel gorivo, biodizel RME, mešavina goriva, supstitucija goriva.

\title{
PRESSURE ANALYSE INDICATORY DIAGRAMS OF DIESEL ENGINE WITH DIESEL FUEL D-2, BIODIESEL RME AND THEIR MIXTURE
}

\section{Summary:}

In view of the fact that the reserves of petroleum, i. e. of fuels mineral origin are limited, the trend of research of renewable sources is more and more actual, with the aim to substitute conventional fuels. During the last years, the trend og substituting gasohol of mineral origin with the fuels deriving from vegetable culture is actual world-wide. EU directives are pointed out that is necessary to substitute fossil diesel with $0,75 \%$ of biofuel per year. In total consumtion of fuels for transportation, to 2010 the biofuel should participate with 5,75\% and with 20\% to 2020. In this review are technology of biodiesel production and reaserch dieselmotor S-44 with use diesel D-2 fuel, biodiesel RME and their mixtures. The results of the researches suggest that further improvement of such fuels is necessary, and particulary of the physical and chemical characteristics, according to the proposed standard for biodiesel.

Key words: diesel-motor, diesel fuel, biodiesel RME, mixture fuels, substitute fuel.

\section{Uvod}

Više od jednog veka eksploatacija energenata raste eksponencijalno. Svetske rezerve nafte, januara 1992. godine, procenjene su na $134,6 \cdot 10^{9} \mathrm{t}$ [1]. Smatra se da će se ovim tempom nafta eksploatisati još 40 do 50 godina, pod pretpostavkom da se ne nađu nova nalazišta. Sve je više onih koji uviđaju ovaj problem i hvataju se u koštac sa problemom supstitucije fosilnih goriva. Logično je da će se na ovom problemu raditi, pre nego što će se bitnije menjati konstrukcija postojećih motora. To je jedna od osnovnih pretpostavki uspešne zamene fosilnih goriva drugim vrstama goriva. Nova vrsta goriva morala bi da bude obnovljiva [2]. Sa- 
gledavajući ovaj problem dosadašnja rešenja treba tražiti u uvođenju u širu upotrebu prirodnog zemnog gasa i nekonvencionalnih vrsta goriva na bazi biljnih ulja, a dugoročno na bazi vodonika.

Problem zagrevanja Zemlje uvodi i nove kriterijume za alternativna goriva.

Godišnje potrebe za dizel gorivom u Srbiji iznose oko 1300000 ta za dizel gorivom samo u poljoprivredi i šumarstvu oko 700000 t. Sopstveni izvori nafte obezbeđuju oko $30 \%$ potreba ili oko 400000 t po godini. Taj problem mogao bi se rešiti proizvodnjom biodizela od uljnih kultura sa 5 do $6 \%$ ukupnih oraničnih površina, a da se pri tome dobije $1000 \mathrm{l} / \mathrm{ha}$ biodizela.

Kada je reč o uvođenju biodizela $u$ upotrebu, može se konstatovati da se u Evropi proizvode značajne količine [3]. Najveći napredak postigla je Francuska, što se odrazilo i na njen smanjen uvoz naftnih derivata. U svetu najveći napredak u tehnologiji proizvodnje i korišćenju biodizela postižu USA i Kanada.

Sadašnji kapaciteti u Srbiji omogućavaju proizvodnju oko $100000 \mathrm{t}$ biodizela godišnje. Tehnologija i oprema za proizvodnju je osvojena, a moguća proizvodnja zavisi od poštovanja predloženih standarda [3]. Potrošnja dizel goriva u Vojsci Srbije je velika, a poznati uslovi koji su nastali u periodu 1992-1994. godine prouzrokovali su otežano izvršenje zadataka, pa je i borbena gotovost bila umanjena.

\section{Fizičko-hemijske karakteristike biodizela RME}

U biljkama uljanih kultura fotosintezom i ostalim neophodnim procesima sintetizuju se lipidi. U odnosu na vreme kada je nafta nastala, po najprihvatljivijim teo- rijama, procesi biosinteze se nisu promenili. Naravno, razlika u godinama nastanka je ogromna. Kod biljnih kultura dovoljna je jedna godina da se sintetizuje ulje. Ovako nastalo ulje može se modifikovati u fabrikama, tako da se od triglicerida esterifikacijom dobiju metilestri masnih kiselina koji imaju slične osobine kao i određeni destilati nafte. Radi se o veoma sličnim jedinjenjima, pa je očigledna mogućnost da se primenjuje kao gorivo za motore sa unutrašnjim sagorevanjem.

Metilestri masnih kiselina od 14 do 18 ugljenikovih atoma imaju slične hemijske i fizičke osobine kao i odgovarajući parafini od 14 do 20 uglje nikovih atoma u lancu [4]. Biljna ulja su trigliceridi i imaju tri puta veću molekulsku masu od jednog molekula metilestra masnih kiselina. Naime, trigliceridi imaju visoku tačku ključanja i zato ne mogu da se koriste kao zamena gorivu za dizel motore.

Biljno ulje, kao najvažnija komponenta za proizvodnju biodizela, dobijeno je iz semena uljnih kultura jeftinom ratarskom tehnologijom. Obrađena je uljana repica kao seme uljne kulture. Ulje uljane repice po kvalitetu je najpogodnije za biodizel gorivo, jer sadrži veoma dobar odnos pojedinih kiselina u svom sastavu, mada se biodizel u svetu dobija od skoro svih poznatih uljanih kultura. Druga biljna kultura od koje se najčešće dobija biodizel je palma (palmino ulje).

Naročito je važno da ulja sadrže manji procenat nižih masnih kiselina, jer njihovi metilestri lakše isparavaju na radnoj temperaturi motora. Zbog toga takvo biodizel gorivo ima povoljnu nisku temperaturu paljenja, što je povoljno za zimske uslove rada motora. 
Kao i svaka industrijska reakcija i ova esterifikacija nije savršena, pa ne daje $100 \%$ prinosa. U konačnom proizvo$\mathrm{du}$, pored metilestra, nalaze se svi učesnici reakcije koji na neki način narušavaju kvalitet stvorenog goriva. Tehnološki proces mora se strogo kontrolisati da bi se sačuvao kvalitet proizvoda. Konačni proizvod treba da ispunjava zahteve odgovarajucih standarda. Jedan takav standard prikazan je u tabeli 1 .

Tabela 1

Karakteristike biodizel goriva od uljane repice koje odgovaraju standardu ÖNORM C 1190 (austrijski Institut za standardizaciju)

\begin{tabular}{|c|c|c|c|}
\hline $\begin{array}{l}\mathrm{R} . \\
\mathrm{br} \text {. }\end{array}$ & Parametar & $\begin{array}{c}\text { Jedinica } \\
\text { mere }\end{array}$ & Vrednost \\
\hline 1. & Potrošnja vazduha & $\mathrm{mol} / \mathrm{kg}$ & 427 \\
\hline 2. & Kalorična vrednost & $\mathrm{MJ} / \mathrm{kg}$ & 37 \\
\hline 3. & Cetanski broj & & $\max .48$ \\
\hline 4. & Tačka zamućivanja & ${ }^{\circ} \mathrm{K}$ & 267,15 \\
\hline 5. & Tačka začepljenja & ${ }^{\circ} \mathrm{K}$ & $\begin{array}{c}\text { za leto } 273,15 \\
\text { a za zimu } \\
258,15\end{array}$ \\
\hline 6. & Gustina na $288,15^{\circ} \mathrm{K}$ & $\mathrm{g} / \mathrm{cm}^{3}$ & $0,87-0,89$ \\
\hline 7. & Koeficijent promene gustine & $\mathrm{g} / \mathrm{cm}^{3} \mathrm{~K}$ & 0,833 \\
\hline 8. & $\mathrm{C}$ & $\%$ & 77,6 \\
\hline 9. & $\mathrm{H}$ & $\%$ & 12,1 \\
\hline 10. & $\mathrm{~S}$ & $\%$ & 0,02 \\
\hline 11. & $\mathrm{O}$ & $\%$ & 10,4 \\
\hline 12. & Entalpija isparavanja & $\mathrm{kJ} / \mathrm{mol}$ & 26 \\
\hline 13. & Tačka isparenja & ${ }^{\circ} \mathrm{K}$ & $193-194$ \\
\hline 14. & $\begin{array}{l}\text { Kinematska viskoznost na } \\
293,15^{\circ} \mathrm{K}\end{array}$ & $\mathrm{mm}^{2} / \mathrm{s}$ & $6,5-9,0$ \\
\hline 15. & $\begin{array}{l}\text { Kin ematska viskoznost na } \\
373,15^{\circ} \mathrm{K}\end{array}$ & $\mathrm{mm}^{2} / \mathrm{s}$ & $1,7-2,3$ \\
\hline 16. & Tačka stvaranja dima & ${ }^{\circ} \mathrm{K}$ & 413,15 \\
\hline 17. & Tačka očvršćavanja & ${ }^{\circ} \mathrm{K}$ & 267,15 \\
\hline 18. & Toksičnost & LD50 & $>2000$ \\
\hline 19. & Napon pare na $293,15^{\circ} \mathrm{K}$ & $\mathrm{kPa}$ & $<0,1$ \\
\hline 20. & Napon pare na $373,15^{\circ} \mathrm{K}$ & $\mathrm{kPa}$ & 5,3 \\
\hline 21. & Isparljivost (TGA) na $473,15^{\circ} \mathrm{K}$ & $\%$ & 13 \\
\hline 22. & Isparljivost (TGA) na $573,15^{\circ} \mathrm{K}$ & $\%$ & 100 \\
\hline 23. & \begin{tabular}{l|l} 
Sadržaj vode \\
\end{tabular} & $\%$ & $<0,01$ \\
\hline
\end{tabular}

\section{Matematički model za analizu snimljenog indikatorskog dijagrama dizel motora sa direktnim ubrizgavanjem}

Indiciranje je snimanje promene pritiska u cilindru motora $\mathrm{u}$ zavisnosti od hoda klipa ili od ugla kolena kolenastog vratila [5]. Matematički model je poslužio da se snimljeni tok parcijalnih pritisaka obradi. Nakon toga, tim istim modelom vrši se obrada rezultata indiciranja.

Poznato je da su procesi u motoru nestacionarnog karaktera [6], čak i pri stacionarnim režimima rada. Veličine stanja u radnom prostoru su, takođe, nestacionarnog karaktera. Ove činjenice zahtevaju dosta skupu opremu pri merenjima. Zbog toga veličinama koje se mere treba posvetiti posebnu pažnju. Pored toga, treba voditi računa i o značaju izmerenih veličina. Na primer, izmereni tok pritisaka gasa na nekom mestu radnog prostora daje mogućnost da se odredi tok sagorevanja, tok sila na motornom mehanizmu, tok srednje temperature (po masi) gasa $\mathrm{u}$ cilindru, tok koeficijenta količine vazduha u cilindru, tok gubitka radne sposobnosti gasa u cilindru, itd.

U ciljeve analize snimljenog indikatorskog dijagrama spada određivanje toka sagorevanja i toka srednje temperature gasa (po masi), kao i specifičnog rada po ciklusu. Tok sagorevanja neophodno je poznavati, kako zbog analize ispitivanog motora, tako i zbog graničnog uslova za modeliranje stvarnog radnog ciklusa ispitivanog motora [6].

Pri obradi snimljenog indikatorskog dijagrama polazi se od osnovnih zakona (prvi zakon termodinamike, zakon o održanju mase, itd.). Pri to me je poznat tok pritisaka, a traži se tok sagorevanja. Kao i u svakom istraživanju, i ovde su u početku usvajani prostiji modeli da bi vremenom bili sve složeniji i savršeniji. Prvo je uvedena pretpostavka da je gas idealan i da ima konstantne specifične toplote i da nema gubitka mase kroz nezaptivena mesta. 
Kompjuterski podržane metode uzimaju u obzir promenljivost eksponenta izentrope $\mathrm{u}$ funkciji temperature i trenutnog sastava gasa u cilindru, ali se prelaz toplote razmatra aproksimativno.

Disocijacija i realnost gasa u cilindru dugo se nije uzimala u razmatranje, a pretpostavljana je apsolutna zaptivenost cilindra. Promena mase gasa za vreme sagorevanja zanemarivala se ili je primenjivana Vibeovom funkcijom. Takvi metodi analize indikatorskog dijagrama nisu u potpunosti kompatibilni sa metodama savremenog matematičkog modeliranja radnih procesa (mada bi, u suštini, trebalo da budu inverzni u odnosu na metod modeliranja radnih procesa). Vidan napredak u tom pogledu, nesumnjivo, predstavlja metod Krigera i Bormana, koji je kompatibilan sa metodom matematičkog modeliranja radnog procesa, što je prikazano u [7]. Ovim metodom se egzaktno uzima u obzir promena mase gasa u cilindru za vreme sagorevanja, usled ubrizgavanja goriva i sagorevanja, i disocijacije gasa. Međutim, gubici usled nezaptivenosti cilindra i realnost gasa nisu uzeti u obzir [6]. Zbog zanemarivanja gubitaka usled nezaptivenosti cilindra metod je primenljiv samo za ispravan motor i normalne režime rada, dok se, na primer, „hladan start" motora ovom metodom ne može istraživati. Metod koji je opisan u [8] u potpunosti je kompatibilan sa opisanim metodom modeliranja i uzima $u$ obzir disocijaciju i nezaptivenost cilindra, tako da se, za razliku od metoda Krigera i Bormana, može primeniti na istraživanje hladnog starta i sl., kada je nezaptivenost cilindra znatna.

U ovom članku prikazan je metod obrade visokopritisnog dela ciklusa koji je u potpunosti kompatibilan sa metodom modeliranja datim u [6], a obrađuje se dizel motor S-44 sa direktnim ubrizgavanjem.

Često se o kompatibilnosti metoda modeliranja sa obradom inidikatorskog pritiska daju pogrešne ocene, polazeći od činjenice da su merenja nedovoljno tačna. Međutim, samo kompatibilni metodi mogu se pouzdano koristiti za međusobnu verifikaciju. Tako se modeliranjem može proizvesti deterministički tok pritisaka, čijom se obradom mora dobiti identičan (do unapred zadatog malog odstupanja) tok sagorevanja, tok temperature gasa u cilindru, itd., koji su bili dobijeni odnosno zadati pri modeliranju. Uvođenjem stohastičkih poremećaja na modelirani deterministički signal moguće je modelirati proces merenja, a zatim primeniti metod obrade koji mora dati rezultate slične modeliranim, jer, inače, metod obrade nije pogodan za obradu merenih podataka.

$\mathrm{Za}$ izvođenje matematičkog modela za obradu snimljenog indikatorskog pritiska usvojiće se sledeće pretpostavke:

- promena stanja gasa je ravnotežna. Pritisak, temperatura i sastav gasa su u svakom trenutku isti na svim mestima cilindarskog prostora. Rad trenja se zanemaruje;

- realni tok stvaranja smeše i sagorevanja goriva zamenjuju se dovođenjem ekvivalentne (vremenski promenljive) mase goriva koja trenutno sagori i energije. Ubrizgana, a nesagorela masa goriva se zanemaruje;

- gubici mase kroz nezaptivena mesta postoje samo za vreme visokopritisnog dela ciklusa;

- kinetička energija gasa u cilindru se zanemaruje. 
Za obradu snimljenog indikatorskog dijagrama uzeće se u obzir četvorotaktni dizel motor S-44 sa direktnim ubrizgavanjem, disocijacija i realnost gasa u cilindru (tj. zavisnost specifičnih toplota i gasne konstante od trenutnog pritiska, temperature i sastava), promenljivost mase usled dovođenja goriva i sagorevanja i nezaptivenosti cilindra, prelaz toplote, kontinualna promena sastava ravnotežnog gasa i realni tok otvaranja usisnog i izduvnog sklopa.

Za vreme procesa sabijanja stvarno ne postoji proces sagorevanja, ali će se analiza primeniti i na proces sabijanja, jer je na taj način omogućena i kontrola kvaliteta snimljenog indikatorskog dijagrama. Naime, za vreme procesa sabijanja trebalo bi da je količina energije dobijena sagorevanjem, odnosno masa koja je u tom periodu ubrizgana i sagorela, ravna nuli. Međutim, zbog greške merenja i eventualne obrade ovaj uslov nikad nije egzaktno ispunjen, pa će se definisati i odgovarajući kriterijumi ocene greške merenja.

\section{Analiza indikatorskog dijagrama dizel motora sa direktnim ubrizgavanjem}

Pri analizi snimljenog indikatorskog dijagrama dizel motora pritisak u cilindru je zadat, tj. unosi se kao ulazni podatak sa datoteke koja sadrži podatke o indiciranom pritisku konkretnog dizel motora, prethodno obrađenom i pripremljenom za analizu.

Model za analizu sastavljen je od sistema običnih nelinearnih diferencijalnih jednačina. Da bi se navedeni sistem mogao rešiti neophodno je poznavati početne uslove, tj. stanje gasa na početku procesa sabijanja: pritisak, temperaturu i ko- eficijent viška vazduha. Sistem se rešava primenom numeričkih metoda integracije. Za potrebe ovog rada primenjena je Ojlerova metoda prediktor-korektor sa iterativnom obradom podataka.

Ako su poznate vrednosti funkcija na početku $j$-tog koraka $y_{i}\left(a_{i}\right)=y_{i, j}$ nalazi se rešenje na kraju koraka $y_{i}\left(a_{i}+? a\right)=y_{i, j}$ tako što se prvo nađe gruba vrednost rešenja po tzv. prediktor formuli:

$$
y_{i, j+1}=y_{i, j}+? a \times f_{i}\left(a_{i}, y_{1, j}, y_{2, j}, \ldots \ldots . . y_{N, j}\right)
$$

Zatim se pronalazi precizno rešenje po tzv. korektor formuli:

$$
\begin{aligned}
& y_{i, j+1}^{(K)}=y_{i, j}+\frac{? a}{2}\left(f_{i}\left(a_{j}, y_{1, j}, y_{2, j}, \ldots \ldots . y_{N, j}\right)+\right. \\
& \left.+f_{i}\left(a_{j+1}, y_{1, j+1}^{(K-1)}, y_{2, j+1}^{(K-1)}, \ldots \ldots . y_{N, j+1}^{(K-1)}\right)\right)
\end{aligned}
$$

\section{$K$ - broj iteracije.}

Iteracija se dalje nastavlja sve dok se ne dobije apsolutna vrednost razlike dve poslednje iteracije koja je manja od neke unapred zadate vrednosti $\varepsilon_{i}$ :

$$
?_{i}=\left|y_{i, j+1}^{(K)}-y_{i, j+1}^{(K-1)}\right|<e_{i}
$$

Glavni program za analizu indikatorskih pokazatelja rada dizel motora je ANID, a poziva, po potrebi, odgovarajuće potprograme $\mathrm{i}$ vrši upis izračunatih vrednosti. Potprogrami su:

- TERMO - potprogram za izračunavanje termodinamičkih osobina vazduha i produkata sagorevanja;

- PRETOP - potprogram za proračun prelaska toplote u cilindru motora; 


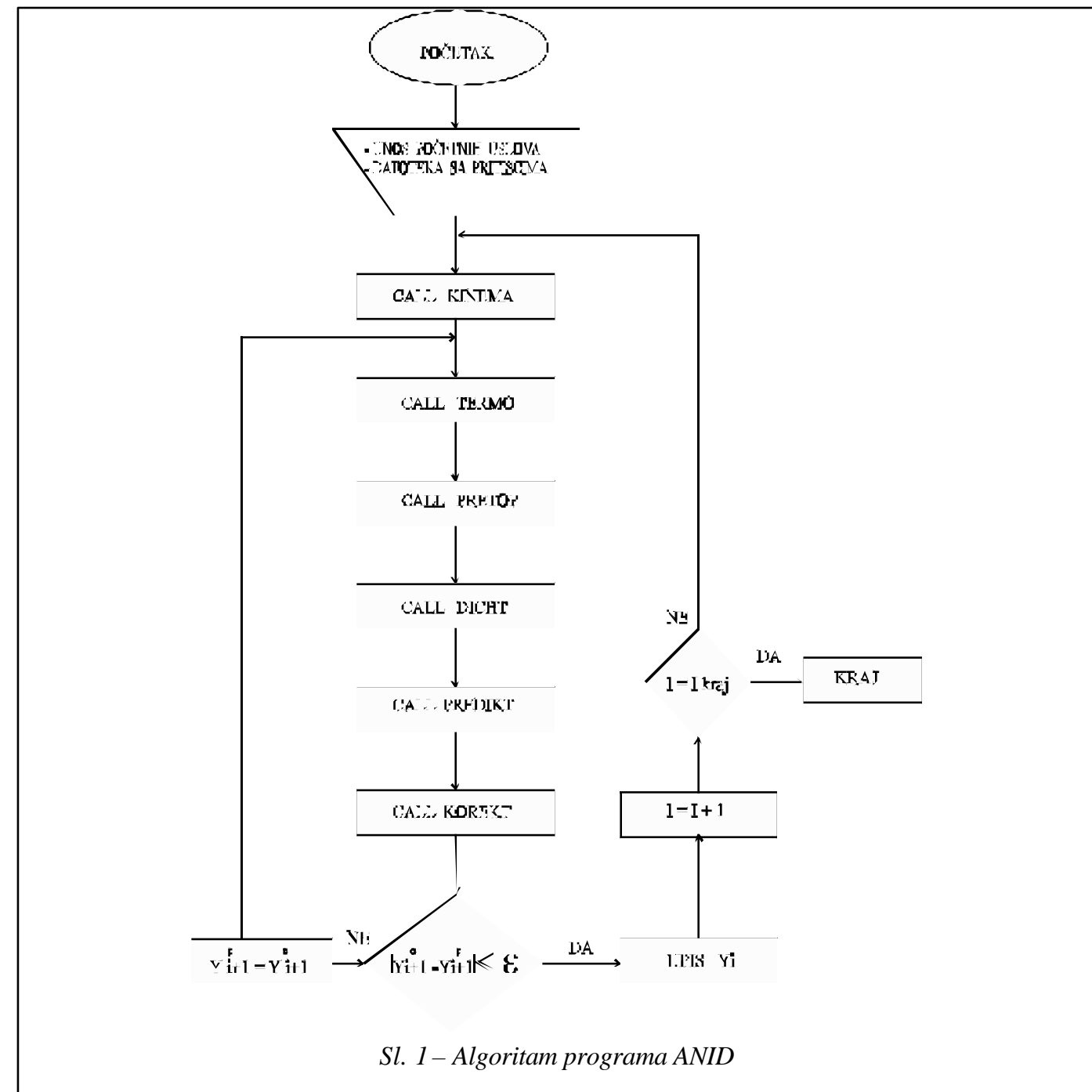

- DICHT - potprogram za izračunavanje gubitaka mase usled nehermetičnosti cilin dra;

- KINEMA - potprogram za izračunavanje kretanja motornog mehanizma;

- DESNA - potprogram za izračunavanje desnih strana diferencijala jednačina;

- PREDIKT - potprogram za numeričku integraciju po prediktor formuli;

- KOREKT - potprogram za numeričku integraciju po korektor formuli.

\section{Rezultati analize indikatorskog dijagrama dizel motora sa direktnim ubrizgavanjem}

Prikazani rezultati analize visokopritisnog dela indikatorskog dijagrama odnose se na dizel motor S-44 sa direktnim ubrizgavanjem. Podaci koji se mogu dobiti analizom indikatorskog dijagrama raznovrsni su. Najčešći rezultati analize indikatorskog dijagrama su: određivanje 


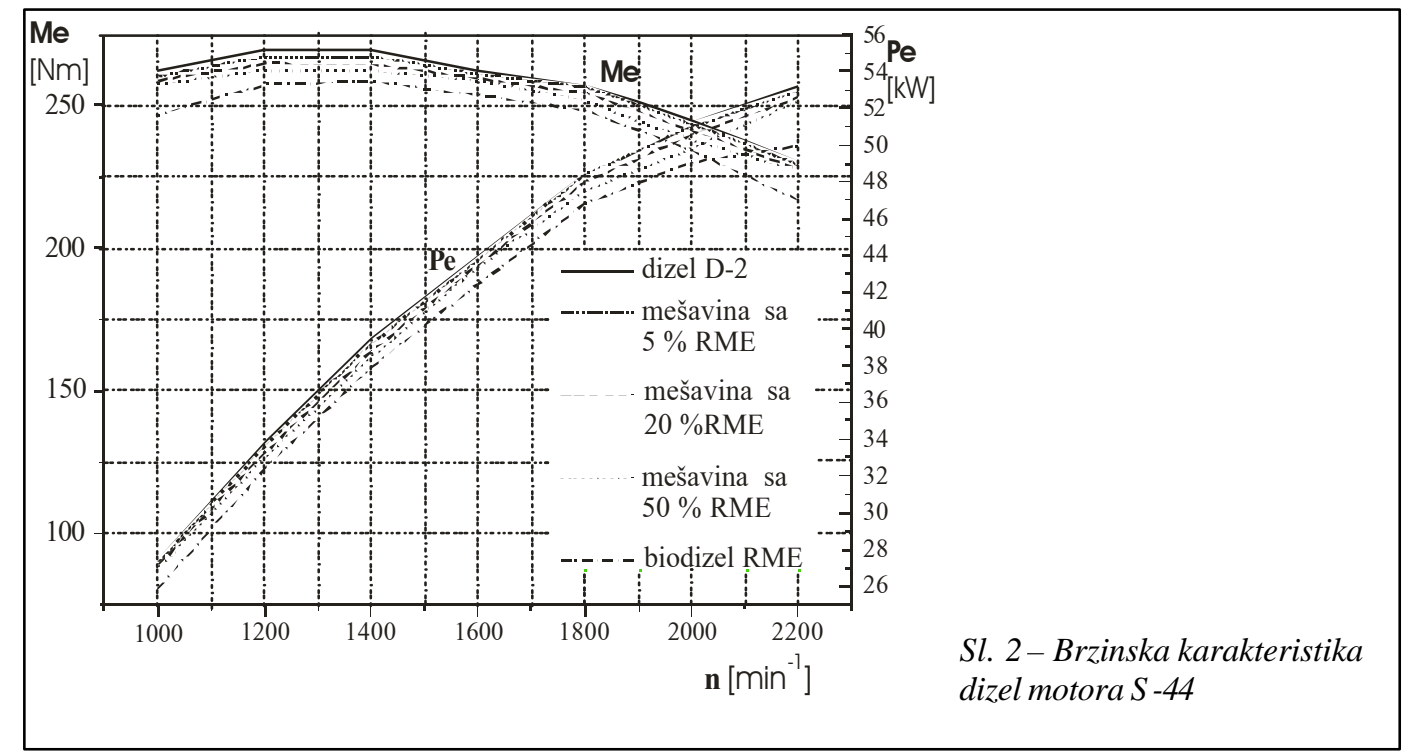

toka sagorevanja (diferencijalnog $\mathrm{i}$ integralnog), toka srednje temperature gasa (po masi), kao i specifičnog rada ciklusa. Pri tome je tok sagorevanja potrebno poznavati kako za analizu sagorevanja kod ispitivanog motora, tako i kao granični uslov za modeliranje stvarnog radnog ciklusa motora. Na dijagramima su prikazani dobijeni rezultati.

Toplotna moć biodizela RME je manja $(36,9 \mathrm{MJ} / \mathrm{kg}) \mathrm{u}$ odnosu na dizel gorivo D-2 $(41,78 \mathrm{MJ} / \mathrm{kg})$. U ispitivanju su korišćene i mešavine dizel goriva D-2 i biodizela RME u odnosima 95\% dizel goriva D-2 i 5\% biodizela RME, $80 \%$ dizel goriva D-2 i $20 \%$ biodizela RME i $50 \%$ dizel goriva D-2 i 50\% biodizela RME.

Sa gorivima i njihovim mešavinama izvršeno je snimanje brzinske karakteristike. Brzinske karakteristike nisu potpune, jer pri snimanju nisu radili merači specifične potrošnje goriva (sepeleri). I pored toga, može se uočiti da najveću snagu $P e$ i moment $M e$ dizel motor S-44 postiže ko- rišćenjem dizel goriva $\mathrm{D}-2$. To se moglo $\mathrm{i}$ očekivati, jer ovo gorivo ima i najveću toplotnu moć. Biodizel RME ima nešto niži procenat ugljenika $(77 \%)$ i vodonika $(12,1)$ u odnosu na dizel gorivo D-2 (87\% ugljenika i $13 \%$ vodonika) [4] i povećanu količinu kiseonika $(10,4 \%)$ (nema ga u dizel gorivu D-2) i fosfora (nema ga u dizel gorivu D-2), a ne sadrži sumpor (u dizel gorivu D-2 sumpora može biti i do 5\%). To mu je prednost po pitanjima korodivnog dejstva na delove motora i negativnog uticaja na životnu okolinu.

Na slici 2 vidi se da mešavina sa $95 \%$ dizel goriva D-2 i 5\% biodizela RME daje slične rezultate kao i dizel gorivo D-2 kada je u pitanju snaga $P e$ i moment $M e$. Maksimalna snaga motora sa ovim gorivom je manja za $0,6 \%$, dok je moment manji za $0,8 \%$, što su vrednosti koje bitno ne utiču na eksploataciju motora. Razlika između rada motora sa dizel gorivom D-2 i biodizelom RME je nešto veća. Snaga je manja za $8,1 \%$, a moment za $4,9 \%$. 


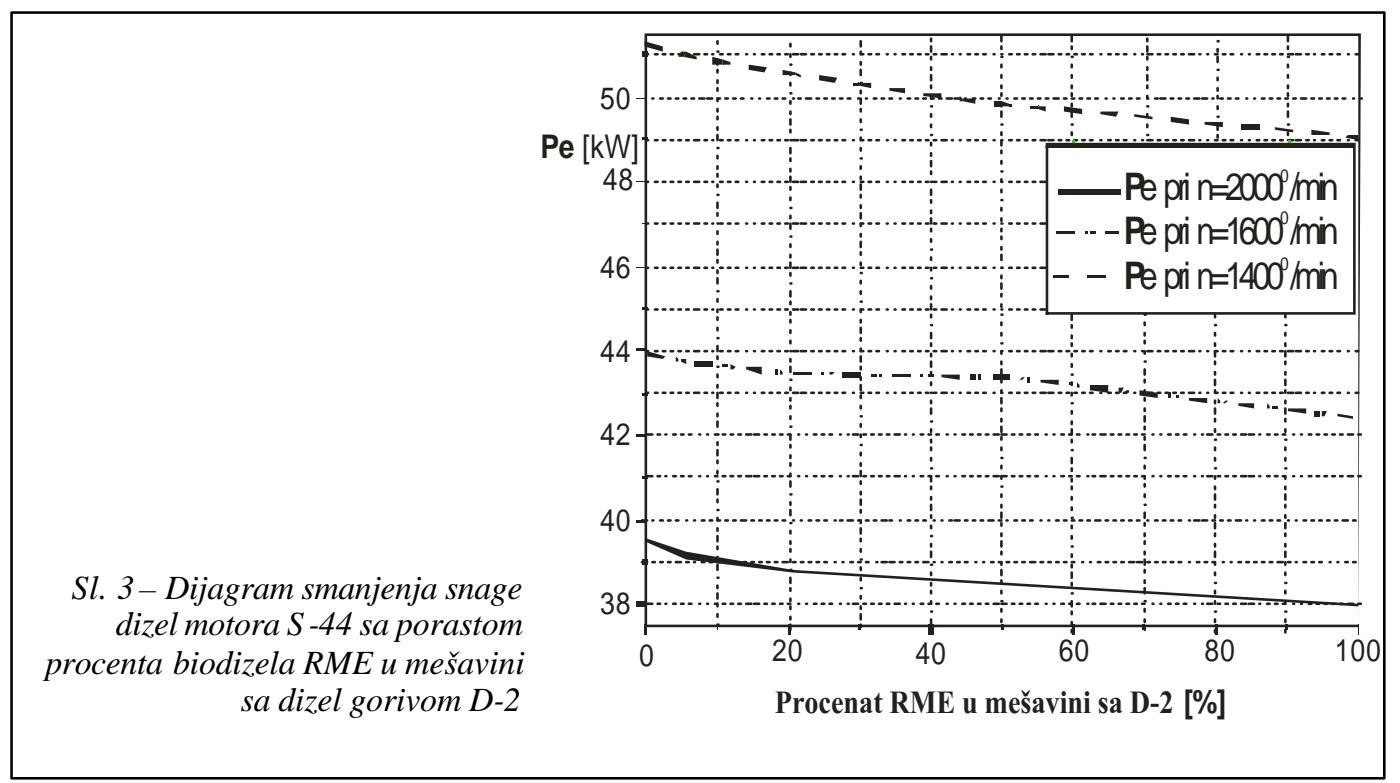

Dijagram na slici 3 prikazuje smanjenje snage motora $P e$ u odnosu na povećanje procenata biodizela RME u mešavini sa dizel gorivom D-2 na različitim brojevima obrtaja kolenastog vratila. Krive koje pokazuju smanjenje snage približno su linearne. Pri povećanju procenta biodizela RME u gorivu snaga motora opada: pri $\mathrm{n}=2000^{\circ} / \mathrm{min}$ snaga opadne za $2,2 \mathrm{~kW}$, pri $\mathrm{n}=1600 \% \mathrm{~min}$ za $1,55 \mathrm{~kW}$, a pri $\mathrm{n}=1400 \% / \mathrm{min}$ za $1,54 \mathrm{~kW}$.

Da bi se započela analiza indikatorskog dijagrama potrebno je „ispeglati“ vrednosti pritiska dobijene merenjem. $\mathrm{Na}$ slici 4 prikazan je ,ispeglan“ integralni tok pritiska za sve vrste goriva koje su korišćene.

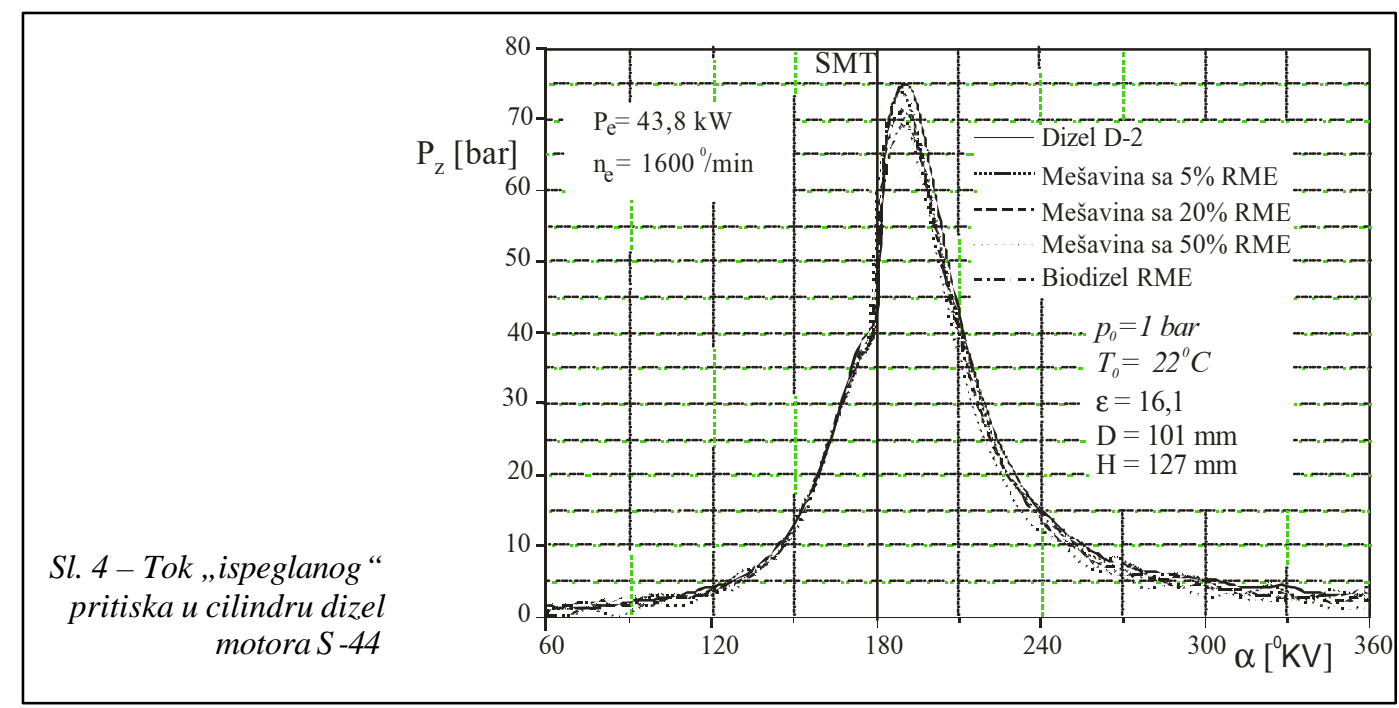




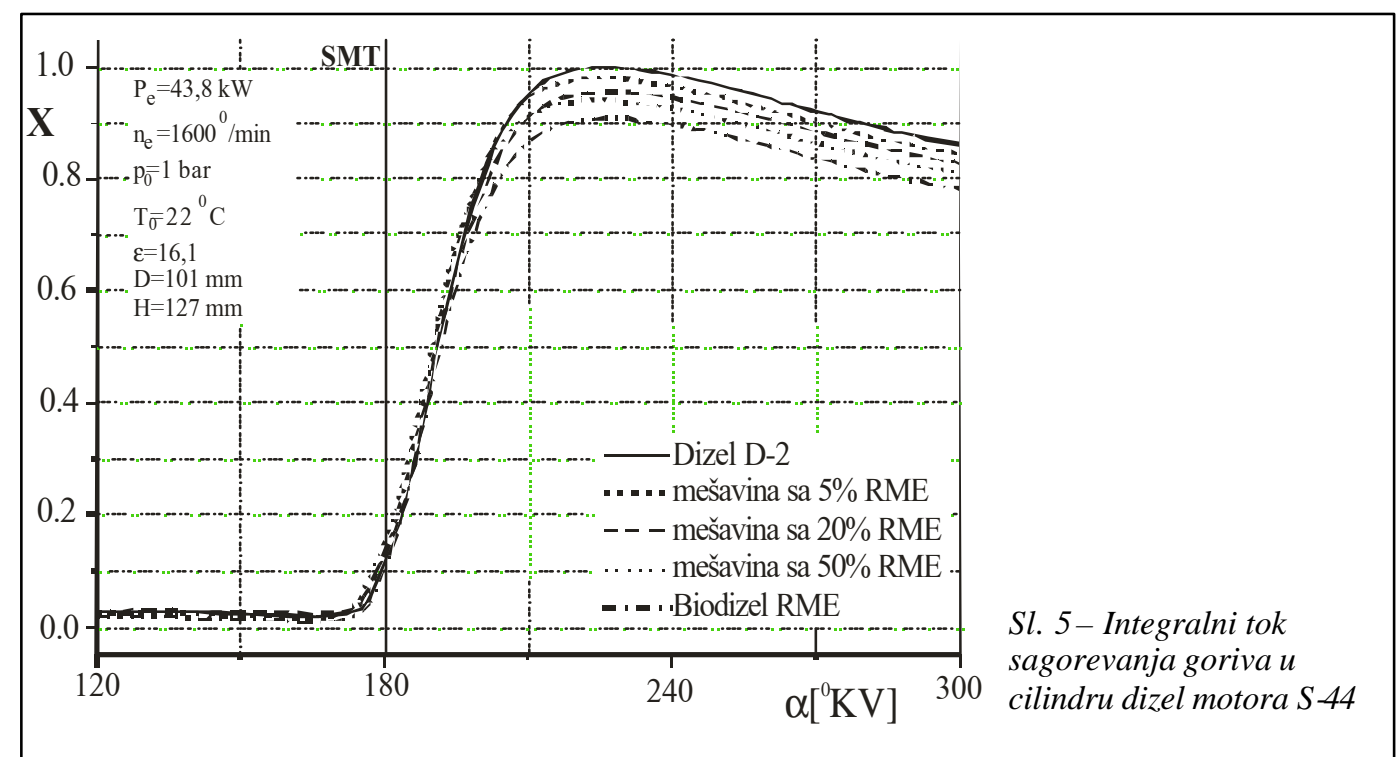

Integralni tok sagorevanja za analizirana goriva (slika 5) prikazuje tok do kraja sagorevanja. Primećuje se da je potpuno sagorelo dizel gorivo D-2, a ostale primenjene vrste goriva nisu u pot-

punosti sagorele. Sa najmanjim procentom sagorelog goriva od $92 \%$ prikazan je biodizel RME, dok je dizel D-2 sagoreo u cilindru sa $99,9 \%$. Ostale mešavine goriva sagorevale su: mešavina u kojoj je

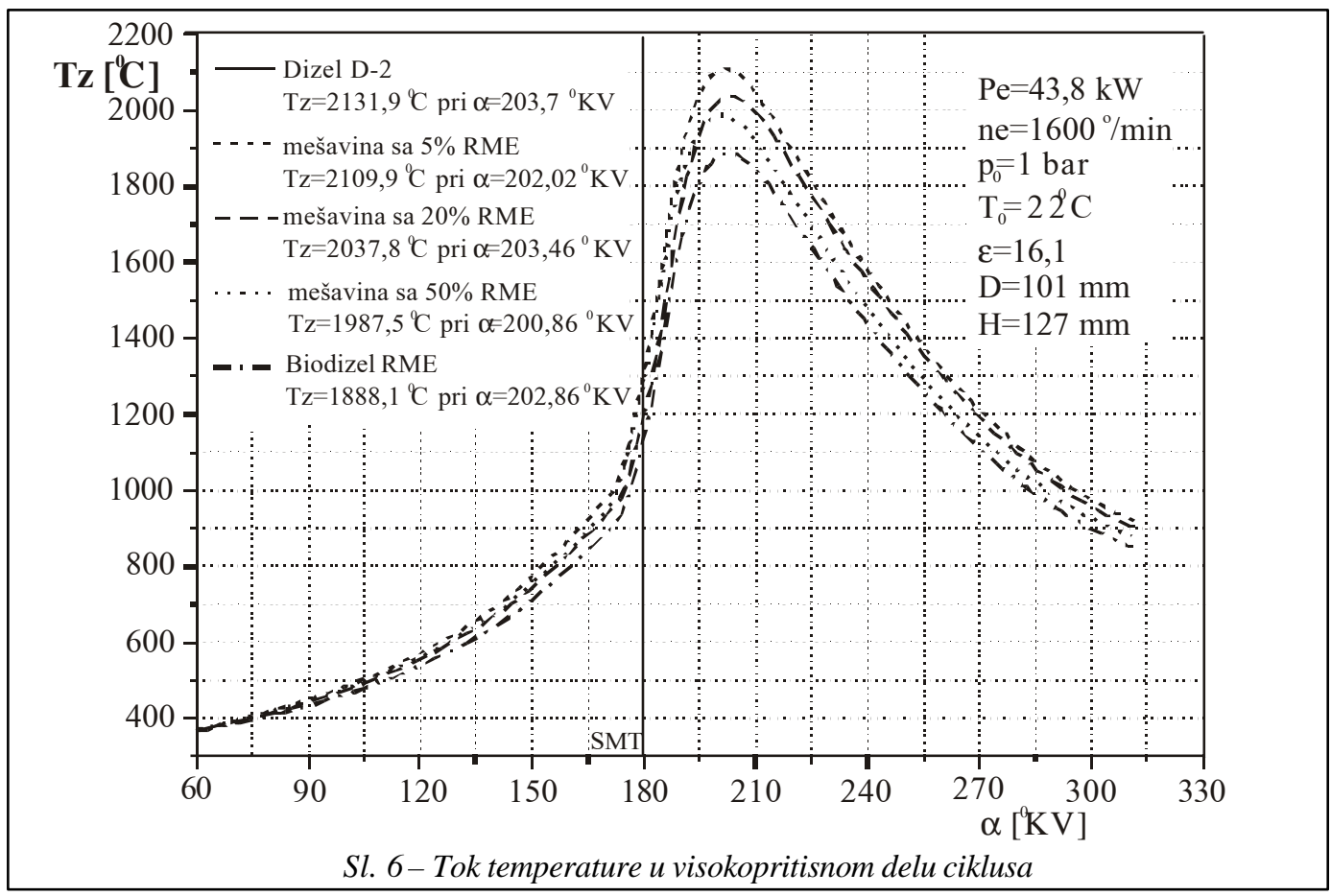




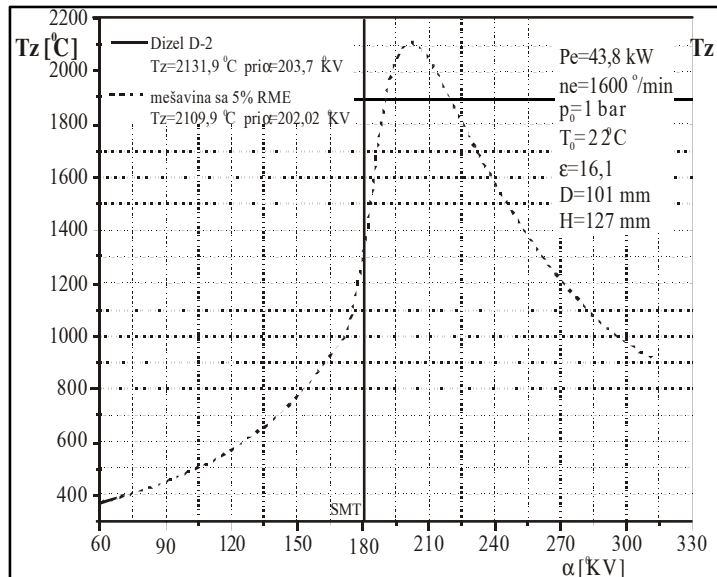

a) Dizel gorivo D-2 i mešavina sa 5\% biodizela RME

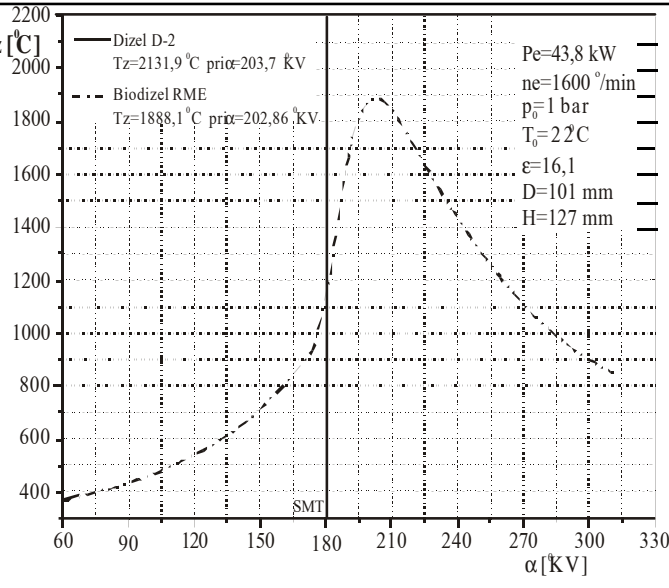

b) Dizel gorivo D-2 i Biodizel RME

\section{Sl. 7- Uporedni tok temperature u dizel motoru S-44}

5\% biodizela RME sa $98,1 \%$, mešavina sa $20 \%$ biodizela RME $95,6 \%$, a mešavina sa $50 \%$ biodizela RME 94,2\%. Može se konstatovati da bi procenat sagorelog goriva bio veći da je za sve vrste analiziranih goriva korigovan regulator količine goriva na pumpi visokog pritiska, u zavisnosti od energetske vrednosti goriva.

Slike 6 i 7 prikazuju tok temperature gasa u cilindru dizel motora S-44 za analizirana goriva.

Najvišu temperaturu u cilindru dizel motora razvilo je dizel gorivo D-2 od $2131,9^{\circ} \mathrm{C}$, dok najnižu razvijenu temperaturu daje biodizel RME od $1888,1^{\circ} \mathrm{C}$. Ostala primenjena goriva razvijaju sledeće temperature: mešavina u kojoj je 5\% biodizela RME $-2109^{\circ} \mathrm{C}$, mešavina sa $20 \%$ biodizela RME - $2037,8^{\circ} \mathrm{C}$, a mešavina sa $50 \%$ biodizela RME $-1987,5^{\circ} \mathrm{C}$. Očekivalo se da će dizel gorivo D-2 razviti najvišu temperaturu, jer ima i najvišu toplotnu moć. Biodizel RME je razvio najnižu temperaturu, jer ima i najnižu donju toplotnu moć. Što se tiče mešavine sa $5 \%$ biodizela
RME, ona daje nešto manju temperaturu gasa u cilindru od temperature koju je sagorevajući razvilo dizel gorivo D-2.

\section{Zaključak}

Fizičko-hemijske karakteristike biodizela RME prikazuju ovo gorivo sa nižim procentom ugljenika i vodonika u odnosu na dizel gorivo D-2 i povećanom količinom kiseonika i fosfora (nema ih u dizel gorivu D-2). U biodizelu RME nema sumpora, a u dizel gorivu D-2 može ga biti i do 5\%. Prednost biodizela RME je što nema korodivno dejstvo na delove motora i ne utiče negativno na živi svet. Gustina i kinematska viskoznost biodizela RME je veća od istih karakteristika dizel goriva D-2, što otežava upotrebu ovog goriva u zimskim uslovima eksploatacije.

Najveću snagu $P e$ i moment $M e$ dizel motor S-44 postiže korišćenjem dizel goriva D-2, jer ono ima i najveću toplotnu moć (veću od biodizela RME za 4,88 $\mathrm{MJ} / \mathrm{kg}$ ili $11,6 \%$ po [9] i [7]). Mešavina sa 
95\% dizel goriva D-2 i 5\% biodizela RME daje rezultate koji mogu zadovoljiti uslove eksploatacije dizel motora S-44. Čist biodizel RME u dizel motoru ne može da se primeni, jer je snaga $P e$ manja za $8,1 \%$ i moment za $4,9 \%$ u odnosu na rad motora sa dizel gorivom D-2. To se vidi pri padu snage motora pri povećanju procenta biodizela RME u mešavini sa dizel gorivom D-2. Ovaj pad snage je skoro linearan na svim merenim brojevima.

Tokovi dobijenih temperatura u cilindru dizel motora S-44 prikazuju da je najvišu temperaturu razvilo dizel gorivo D-2, a najnižu biodizel RME. Uvođenjem ove vrste goriva, bilo da se radi o mešavini ili čistom gorivu, neće dodatno termički opterećivati delove motora.

Tokovi sagorevanja kod primenjenih goriva su slični, ali procenat nesagorelog goriva raste sa porastom procenta biodizela RME u mešavini. Kako se nije ispitivao ,životni vek motora“ upotrebom biodizela RME, ne može se sa sigurnošću govoriti o problemima koji bi nastali zbog nepotpunog sagorevanja smeše u cilindru, količinama stvorene smole, koksovanja brizgaljki i drugih štetnih pojava.
Uticaj biodizela RME i mešavina na gumene delove i boje nije se ispitivao, što može direktno da utiče na opravdanost primene. Verovatno bi ispitivanja bila povoljnija da je „Prva iskra“ Namenska a. d. imala aditive za poboljšanje karakteristika biodizel RME (u radu je korišćen biodizel RME čija je čistoća $\geq 98 \%$ metil estra, što zahtevaju uvoznici iz Evropske unije).

Literatura:

[1] Bakić, M. i dr.: Korišćenje sirovih biljnih ulja kao goriva u poljoprivredi, Biodizel, monografija, Poljopri vredni fakultet, Novi Sad, 1995.

[2] Furman, T. i dr.: Tečna fosilna goriva i al ternativa, Biodizel, monografija, Poljoprivredni fakultet, Novi Sad, 1995.

[3] Nikolić, R. i dr.: Proizvodnja i potrošnja goriva za dizel motore, Biodizel, monografija, Poljoprivredni fakultet, Novi Sad, 1995.

[4] Živković, M.: Motori sa unutrašnjim sagorevanjem, I deo, Mašinski fakultet, Beograd, 1988.

[5] Živković, M. i Trifunović, R.: Ispitivanje motora sa unutrašnjim sagorevanjem, Mrsinski fakultet, Beograd, 1987.

[6] Jankov, R.: Matematičko modeliranje strujno-termodinamičkih procesa i pogonskih karakteristika dizel motora, Naučna knjiga, Beograd, 1984.

[7] McAulay K. J., Wu Tang, Schen Simon K., Borman G. L., Myers P. S., Uyehara O. A.: Development and evalution of the simulation of the compres sion-ingnition engine, SAE Preprints, s. a. Nr. 650451.

[8] Jankov, R.: Opšti metod proračuna i analize stvarnog radnog ciklusa motora SUS sa konstantnim pritiscima u usisnom i izduvnom kolektoru pomoću digitalnog računara, Tehnika-Mašinstvo, 1979

[9] Vereš baranji, I.: Fizičke i hemijske karakteristike metilestra biljnih ulja kao goriva za dizel motore, Biodizel, monografija, Poljopri vredni fakultet, Novi Sad, 1995. 